\title{
Quantifying competition in white spruce (Picea glauca) plantations
}

\author{
Alexa Bérubé-Deschênes ${ }^{1}$ - Tony Franceschini ${ }^{1} \cdot$ Robert Schneider $^{1}$
}

Received: 31 October 2016 / Accepted: 14 February 2017 /Published online: 18 March 2017

(C) INRA and Springer-Verlag France 2017

\begin{abstract}
- Key message In mixed forest plantations in sub-boreal forests with high levels of natural regeneration ingrowth, competition must be quantified differently for each species, with distant-independent indices working better for the planted species and distant-dependent indices for ingrown balsam fir. Although broadleaved competition hinders growth of coniferous species more than coniferous competition, the differentiation between clades is not important enough to improve growth predictions.

- Context The use of ecosystem-based forest management has changed how forest stands are tended. This shift in the management paradigm has led to a higher tolerance in natural ingrowth regeneration in plantations. The correct way of quantifying competition must thus be assessed to develop growth simulators.

- Aims An individual tree relative basal area increment (RBAI) growth model for white spruce, balsam fir and other coniferous and broadleaved species was calibrated.
\end{abstract}

\section{Handling editor: Aaron R Weiskittel}

Contribution of the co-authors Alexa: carried out the field and lab work, data analysis and writing of the manuscript. The work was part of her M.Sc. thesis.

Tony: codirector of the M.Sc. thesis, supervised data analysis and edited the manuscript.

Robert: M.Sc. thesis director, project manager, supervised all of the steps and edited the manuscript.

Robert Schneider

robert_schneider@uqar.ca

1 Chaire de Recherche sur la Forêt Habitée, Département de Biologie, Chimie et Géographie, Université du Québec à Rimouski (UQAR), 300 Allée des Ursulines, Rimouski, QC G5L 3A1, Canada
- Methods Using data obtained from 94 sample plots in 48 white spruce plantations from Eastern Quebec, we considered both linear and nonlinear models of RBAI as a function of site index, tree size and tree competition. The tested distancedependent and distance-independent indices were also discriminated according to competitor clade (conifers or broadleaves).

- Results The best competition index for balsam fir was distance-dependent whereas a distant-independent one was retained for the other species groups. Moreover, broadleaved competitors had stronger effect on RBAI for white spruce growth when compared to coniferous competitors.

- Conclusion Competition must be quantified depending on if the species is planted or ingrown. However, dividing competition into clades (i.e. coniferous versus broadleaved) is not necessary, at least in the present study.

Keywords Inter- and intra-specific competition - Tree growth $\cdot$ Distance-independent and distance dependant competition indices $\cdot$ Modelling

\section{Introduction}

Forest management in the province of Quebec was, for a long time, based on harvesting natural forests and was characterized by large areas being harvested by clear-cuts (Del Degan 2010). These practices resulted in important changes in stand structure and composition (Boucher et al. 2006; Boucher et al. 2009). A new Sustainable Forestry Act came into force in 2013 (Ministère des Forêts, de la Faune et des Parcs 2013), and forest management must now be ecosystem-based. This concept aims at maintaining biodiversity and ecosystem variability by reducing the differences between managed and unmanaged forests (Gauthier et al. 2008). As a consequence, 10 
to $20 \%$ of the plantations in Eastern Quebec will be converted from even-aged stands to uneven-aged or irregular stands (Gagné and Lavoie 2014). This conversion can be performed by selection thinning in order to establish new age classes and maintain tree vigour (Schütz 2001; Schütz 2002; Nyland 2003).

In the 1980s, the Government of Quebec implemented a programme to reforest 300 million seedlings per year (Barrette et al. 2014). Some 35 years later, some of these plantations are now ready for a first commercial thinning, with some variations between the regions. For example, more than 36,000 ha of white spruce (Picea glauca) plantations in Eastern Quebec will be ready for a first commercial thinning in the next 5 years (Gagné et al. 2012). These plantations are characterized by important balsam fir (Abies balsamea) and broadleafed ingrowth. A compromise between maintaining the initial investment in white spruce and favouring the natural regeneration must therefore be found. Moreover, the natural ingrowth can help to reduce the differences between managed and unmanaged stands (Gauthier et al. 2008), as prescribed by the new Sustainable Forestry Act. Using growth and yield models can help forest managers better plan their silvicultural treatments, by determining the proportions of each species needed and thinning patterns required to attain their objectives.

In Quebec, only a few models were developed to estimate mixed stand growth. Among them, Artemis-2009 (Fortin and Langevin 2010) and SaMARE (Fortin et al. 2009) are individual tree level models adapted respectively for naturally regenerated forests and for uneven-aged sugar maple (Acer saccharum) stands. The stand level CroirePlant model was developed for white spruce plantations (Prégent et al. 2010). CroirePlant is, however, not calibrated for plantations with large amounts of natural regeneration ingrowth. There is thus a need to develop an individual tree growth model adapted to mixed white spruce plantations which may be used to help forecast stand growth after atypical thinning patterns.

Individual tree growth models can vary in complexity and flexibility depending on their mathematical formulation (linear versus nonlinear models) and how competition is quantified (Schneider et al. 2016). Competition can be assessed using either distance-independent or distance-dependent indices (Daniels et al. 1986). Distance-independent competition (DIC) indices have long been used to quantify the competition within a forest stand (Reineke 1933). They usually perform well in even-aged stands, where spatial variability is low (Pretzsch 2009). Distance-dependent competition (DDC) indices use tree position in order to characterize potential resource acquisition and thus integrate the within-stand structural variation. These indices have also been shown to work well in even-aged stands (Boivin et al. 2010); although, generally, they are used for modelling tree growth in complex stands (Prévosto 2005; Pretzsch 2009; Weiskittel et al. 2011). Moreover, DDC is more suitable than DIC to simulate new silvicultural treatments that aims to convert even-aged stands to uneven-aged ones (Boivin et al. 2010).

Intra-specific competition is known to have a stronger effect on tree growth than inter-specific competition (Pretzsch et al. 2013). In other words, when a tree is surrounded by other species, its growth will be larger than when it is in competition with trees of the same species (Getzin et al. 2006; Pretzsch 2009). This has been used to explain larger stem biomass observed in mixed white spruce-trembling aspen (Populus tremuloides) stands when compared to pure stands of either white spruce or aspen (Wang et al. 1995).

Inter-specific competition was demonstrated to change with stand developmental stage. According to Simard et al. (2004), white birch (Betula papyrifera) competition is stronger in young stands while conifer competition is more important in older ones. Indeed, young white spruce and sub-alpine fir (Abies lasiocarpa) growth and survival are hindered by white birch and trembling aspen (Comeau et al. 2003). Early successional species and shade-intolerant species such as white birch and trembling aspen have higher light use efficiency when compared to late successional species (Valladares and Pearcy 1998; Valladares and Niinemets 2008). These relationships are similar when considering conifers: shadeintolerant conifers like lodgepole pine (Pinus contorta) or jack pine (Pinus banksiana) have higher growth following thinning when compared to shade-tolerant conifers such as Douglas fir (Pseudotsuga menziesii) or black spruce (Simard et al. 2005; Goudiaby et al. 2012). However, the competitive abilities of early successional species decline as mixed stands develop (Simard et al. 2004).

Considering the advent of ecosystem-based forest management, the main objective of the present study is to model the individual tree growth of the main species found in the white spruce plantations of Eastern Quebec. The first sub-objective is to determine the competition index that will best represent the effect of competition on tree growth (e.g. DIC versus DDC). The second sub-objective is to determine which mathematical form (linear versus nonlinear) ought to be used to model tree growth. The third sub-objective is to determine whether the discrimination between conifer and broadleaf competition improves the model performance. To achieve these sub-objectives, three hypotheses were made. The first hypothesis is that distance-dependent competition indices will present better model fit statistics than distance-independent competition indices. As Eastern Quebec white spruce plantations have important natural regeneration ingrowth, stand dynamics and tree interactions are more complex than in monospecific, even-aged plantations. Tree diameter increment is non-linear with tree size, as smaller trees will have larger increments than large ones. Therefore, the second hypothesis is that a linear model will not be able to describe growth as well as non-linear one. Finally, competition in the studied plantations can be grouped by clade (e.g. broadleaf versus 
conifer) because, in the study area, broadleaved species are mainly shade-intolerant species and conifers mainly white spruce and balsam fir, which have similar crown characteristics. The third hypothesis is thus that discriminating conifers and broadleaves competition will significantly improve model performance.

\section{Material and methods}

\subsection{Study area and sites}

A permanent sample plot network of 94 plots within 48 white spruce plantations was established in 2013 in the Bas-SaintLaurent region of Eastern Quebec, Canada (Fig. 1). This region is in the eastern balsam fir-yellow birch bioclimatic subdomain of the boreal mixedwood forest zone. The mean annual temperature and precipitations are $3.1{ }^{\circ} \mathrm{C}$ and $929 \mathrm{~mm}$, respectively (Robitaille and Saucier 1998).
The plantations were chosen with a stratified random sampling scheme based on three criteria available from the provincial ecoforest maps: (i) ecological type, (ii) stand density and (iii) stand height. The four ecological types with the highest proportion of white spruce plantations were retained: sugar maple-yellow birch, balsam fir-yellow birch, balsam fir-white birch and balsam fir-eastern white cedar ecotypes. Within each ecotype, plantations with high (crown cover $>80 \%$ ), moderate (crown cover between 60 and 80\%) and low densities (crown cover between 40 and $60 \%$ ) were then selected. Finally, we retained two classes of dominant height: (i) height between 7 and $12 \mathrm{~m}$ (ii) height between 4 and $7 \mathrm{~m}$. A total of 24 combinations (four ecotypes, three stand densities and two dominant stand height classes) were possible. Two plantations per combination were randomly selected, and within each plantation, two plots were established for a total of 96 permanent sample plots (24 stand types $\times 2$ plantations $\times 2$ sample plots). Two sample plots were discarded as no white spruce trees were found in the plot, yielding a total of 94 plots.

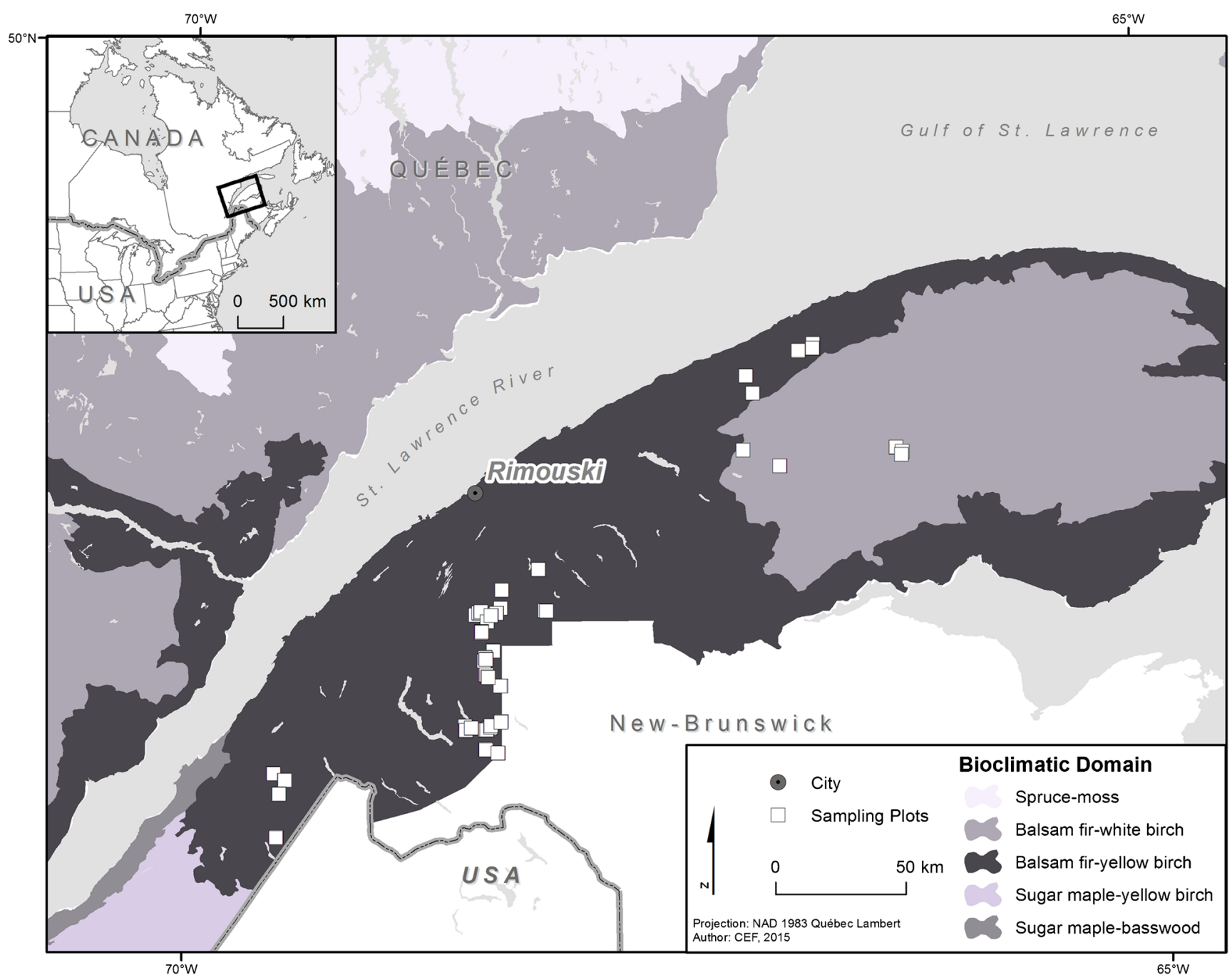

Fig. 1 Permanent sample plot network established in the Bas-Saint-Laurent region of Eastern Quebec (Canada) 


\subsection{Data collection}

Each plot had a radius of $5.64 \mathrm{~m}$ (area of $100 \mathrm{~m}^{2}$ ). All living trees with a diameter at breast height $(\mathrm{DBH})$ greater than $5 \mathrm{~cm}$ were numbered and measured using a diameter tape. An approximate tree map was also sketched in the field. In each plot, height of two randomly selected dominant trees for each species was measured using a Vertex IV Hypsometer. The DBH of the closest trees outside the plot was also measured. The trees were chosen with the following criteria: an outside tree was measured if its crown was in interaction with a tree inside the plot. Interactions were either the crowns touching or the outside tree overshadowed a plot tree. An increment core was extracted on each tree within the plot, with the borer orientated towards the centre of the plot. The cores were sanded, and the 5 -year increment was then measured using an electronic caliper. No increment core was extracted in the closest trees outside the plot. Their DBH 5 years ago was predicted with a linear regression calibrated with the increment core data: $\mathrm{DBH}_{t-5}=-1.25+0.09 \mathrm{DBH}_{t=0}\left(\mathrm{R}^{2}=0.93\right)$. Site indices (SI), defined as plantation dominant height at age 25 , were then calculated for each plantation according the method described in Prégent et al. (2010)

$\mathrm{SI}=34.6683\left[1-\left[1-\left[\frac{\mathrm{HD}}{34.6683}\right]^{\frac{1}{1.5077}}\right]^{\frac{25}{\mathrm{AGE}}}\right]^{1.5077}$

where $\mathrm{HD}$ is the average height of the 100 largest stems ha ${ }^{-1}$ and AGE the age of the plantation. SI ranged between 6.7 and $14.9 \mathrm{~m}$ at 25 years. A summary of the dataset is given in Table 1.

\subsection{Tree maps}

Tree maps of each plot were obtained from terrestrial laser scanner (TLS) data. Each plot was scanned with a FARO Focus 3D from three to four scanning points, in order to reduce occlusion. First, Faro Scene 5.0 (FARO technologies) was used to assemble the multiple scans from each plot to produce a three-dimensional point cloud. Computree (Othmani et al. 2011) was then used to extract a $10 \mathrm{~cm}$ slice centred on $1.30 \mathrm{~m}$ above the digital terrain model. Cloud points belonging to the branches were manually removed from the $10 \mathrm{~cm}$ slice, and the cleaned point cloud was used to determine the XY tree coordinates. This last step was performed using the functions contained in the ' $\mathrm{fpc}$ ' (Martin et al. 1996) and 'pracma' packages (Gander et al. 1994) of the $R$ statistical software (R Development Core Team 2011). The coordinates of each tree within the plot and the first row of trees bordering the plot were thus obtained. Finally, each coordinate was attributed a tree number obtained from the extraction process from the first step. Unidentified tree numbers were manually marked in $\mathrm{R}$ using maps drawn during the forest inventory. To ensure concordance between tree numbers assigned automatically and those given manually, the DBH obtained from the cloud point and the DBH measured in the field was compared.

\subsection{Competition indices}

Competition was quantified with both distance-independent and distance-dependent competition indices, and their mathematical definitions are given in Table 2. Three distanceindependent competition indices were computed: (i) the diameter squared ratio (DRS) (Glover and Hool 1979), (ii) the standardized stand density (SSD) (Reineke 1933) and (iii) the basal area of trees larger than the target tree (BAL) (Wykoff et al. 1982). Four distance-dependent indices were computed: (i) two variants of Hegyi's index (HI1 and HI2) (Hegyi 1974), (ii) the Martin-Ek index (MEI) (Martin and Ek 1984) and (iii) Spurr's point density index (SPDI) (Spurr 1962). For these latter competition indices, competitors of a specific tree were identified using the Voronoi method of the 'tripack' package (Renka et al. 2013) implemented in R (Fig. 2). A Voronoi tessellation partitions the plot into convex polygons. Each polygon is associated to a tree, and every location within a polygon is closer to the tree of that polygon than any other tree in a plot (Voronoï 1908). Specifically, two trees were considered as competitors when they share a common line segment of their Voronoi polygon. In other words, the competitor trees are trees which potentially have touching crowns. As trees outside the plot that had crowns touching, or that overshadowed trees within the plot, were also measured and located with XY coordinates, no correction for edge effects was required. All competition indices were calculated for competitor species pooled together as well as the competitor species separated according to their clades, i.e. conifers and broadleaves. The DRS per clade could not be calculated, since the absence of a clade would lead to a division by 0 . Furthermore, the inverse of the DRS was tested to overcome this pitfall but led to fit statistics which were not as good as those obtained with the DRS (e.g. Akaike's and Bayesian information criterion), and thus $1 / \mathrm{DRS}$ was not further considered.

\subsection{Growth models}

Linear (Eq. 2) and nonlinear (Eq. 3) mixed effects models were developed to predict the relative basal area annual increment (RBAI, in $\mathrm{m}^{2} \mathrm{~m}^{-2}$ year ${ }^{-1}$ ), defined as the basal area increment $\left(\mathrm{m}^{2}\right.$ year $\left.{ }^{-1}\right)$ to basal area $\left(\mathrm{m}^{2}\right)$ ratio, for white spruce, balsam fir, other conifers species and broadleaves species, independently. Random effects were applied on the intercepts for the plantation and plot within plantation hierarchical levels. 
Table 1 Descriptive statistics of dataset with standard deviations in parenthesis

\begin{tabular}{|c|c|c|c|c|c|c|}
\hline Species & $\mathrm{DBH}(\mathrm{cm})$ & $\begin{array}{l}\text { Ring width } \\
(\mathrm{mm})\end{array}$ & $\begin{array}{l}\text { Dominant } \\
\text { height }(m)\end{array}$ & $\begin{array}{l}\text { Number of } \\
\text { individuals }\end{array}$ & $\begin{array}{l}\text { Basal area } \\
\left(\mathrm{m}^{2} \mathrm{ha}^{-1}\right)\end{array}$ & $\begin{array}{l}\text { Stand density } \\
\left(\text { nbstems }^{-1} a^{-1}\right)\end{array}$ \\
\hline White spruce (Picea glauca) & $13.6(4.3)$ & $2.7(1.3)$ & $11.4(2.8)$ & 1048 & $13.4(7.2)$ & $1272.3(668.3)$ \\
\hline Balsam fir (Abies balsamea) & $13.0(5.6)$ & $2.8(1.6)$ & $12.0(3.2)$ & 365 & $4.5(6.2)$ & $453.0(591.5)$ \\
\hline \multicolumn{7}{|l|}{ Other conifers } \\
\hline Black spruce (Picea mariana) & $11.6(3.8)$ & $1.8(1.1)$ & $10.2(2.5)$ & 150 & $1.6(4.7)$ & $180.7(506.7)$ \\
\hline Eastern larch (Larix laricina) & $18.8(6.6)$ & $2.8(1.5)$ & $16.1(4.7)$ & 15 & $0.4(3.1)$ & $18.1(118.1)$ \\
\hline Norway spruce (Picea abies) & $9.5(3.5)$ & $3.3(1.1)$ & $9.6(0.4)$ & 8 & $0.0(0.3)$ & $9.6(87.8)$ \\
\hline Eastern white cedar (Thuja occidentalis) & $6.9(2.6)$ & $0.9(1.0)$ & $4.4(0.0)$ & 2 & $0.0(0.1)$ & $2.4(15.4)$ \\
\hline \multicolumn{7}{|l|}{ Broadleaves } \\
\hline Trembling aspen (Populus tremuloides) & $10.1(5.1)$ & $2.7(1.6)$ & $12.2(3.4)$ & 66 & $0.5(1.5)$ & $80.7(192.2)$ \\
\hline Paper birch (Betula papyrifera) & $8.8(3.7)$ & $1.9(0.9)$ & $9.9(1.3)$ & 32 & $0.2(0.6)$ & $41.0(125.0)$ \\
\hline Sugar maple (Acer saccharum) & $9.9(6.3)$ & $1.5(0.5)$ & $12.1(3.9)$ & 11 & $0.1(0.8)$ & $13.3(58.0)$ \\
\hline Red maple (Acer rubrum) & 7.5 & 2.5 & 7.6 & 1 & 0.1 & 32.5 \\
\hline
\end{tabular}

Bold characters indicate species groups for which models were calibrated

$$
\begin{aligned}
\mathrm{RBAI}_{i j k}= & b_{20}+b_{21} \cdot \mathrm{SI}_{i j}+b_{22} \cdot \ln \left(\mathrm{DBH}_{i j k}\right)+f\left(\mathrm{CI}_{i j k}\right) \\
& +u_{k}+v_{j k}+e_{i j k} \\
\mathrm{RBAI}_{i j k}= & b_{30}+\mathrm{g}\left(\mathrm{SI}_{i j}\right) \cdot h\left(\mathrm{DBH}_{i j k}\right) \cdot f\left(\mathrm{CI}_{i j k}\right)+u_{k}+v_{j k} \\
& +e_{i j k}
\end{aligned}
$$

Where:

- $\quad b_{20}, b_{21}, b_{22}, b_{23}$ and $b_{30}$ are fixed effect parameters estimated by the regressions.

- $\quad$ SI is the site index (in $\mathrm{m}$ ),

- $\mathrm{DBH}$ is the diameter at breast height (in $\mathrm{mm}$ ).

\begin{tabular}{|c|c|c|c|}
\hline & & Equations & References \\
\hline \multirow[t]{4}{*}{ Distance-independent competition indices } & Diameter squared ratio (DRS) & $\mathrm{CI}=\frac{D_{i}^{2}}{\bar{D}^{2}}$ & Glover and Hool (1979) \\
\hline & Standardized stand density (SSD) & $\mathrm{CI}=\frac{1}{500} \cdot N \cdot\left[\frac{\bar{D}}{10}\right]^{1.605}$ & Reineke (1933) \\
\hline & Basal area of larger trees (BAL) & $\mathrm{CI}=\sum_{j}\left[\pi \cdot\left(\frac{D_{j}}{200}\right)^{2}\right] \cdot \frac{10000}{\text { Plot area }}$ & Wykoff et al. (1982) \\
\hline & & For $D_{j} \geq D_{i}$ & \\
\hline \multirow[t]{4}{*}{ Distance-dependent competition indices } & Hegyi's competition index (HI1) & $\mathrm{CI}=\sum_{i \neq j} \frac{D_{j}}{D_{i} \cdot \text { Dist }_{i j}}$ & Hegyi (1974) \\
\hline & Hegyi's competition index (HI2) & $\mathrm{CI}=\sum_{i \neq j} \frac{D_{j}}{D_{i} \cdot\left(\text { Dist }_{i j}+1\right)}$ & Hegyi (1974) \\
\hline & Martin-Ek index (MEI) & $\mathrm{CI}=\sum_{\mathrm{i} \neq \mathrm{j}}\left[\frac{D_{j}}{D_{i}} \cdot e^{\left(\frac{16 \cdot \text { Disti }_{i j}}{D_{i}+D_{j}}\right)}\right]$ & Martin and Ek (1984) \\
\hline & Spurr's point density index (SPDI) & $\mathrm{CI}=\frac{75.625}{\mathrm{n}} \cdot \sum_{i \neq j}\left[\left(\mathrm{j}+\frac{1}{2}\right) \frac{\mathrm{D}_{\mathrm{j}}^{2}}{\mathrm{Dist}^{2}}\right.$ & Spurr (1962) \\
\hline
\end{tabular}

- $f\left(\mathrm{CI}_{i j k}\right)$ is the competition function using the indices listed in Table 2 (see competition effect section below).

Table 2 Tested distance-independent and distance-dependent competition indices

$D_{i}$ DBH of tree $i$ in cm, $D_{j}$ DBH of tree competitor $j$ in $\mathrm{cm}, \bar{D}$ average DBH of trees in the plot in $\mathrm{cm}, N$ number of tree per acre, $n$ number of tree competitors identified by the voronoï method, Dist $t_{i j}$ distance between tree $i$ and tree competitor $j$ in meters, plot area in $\mathrm{m}^{2}$ 


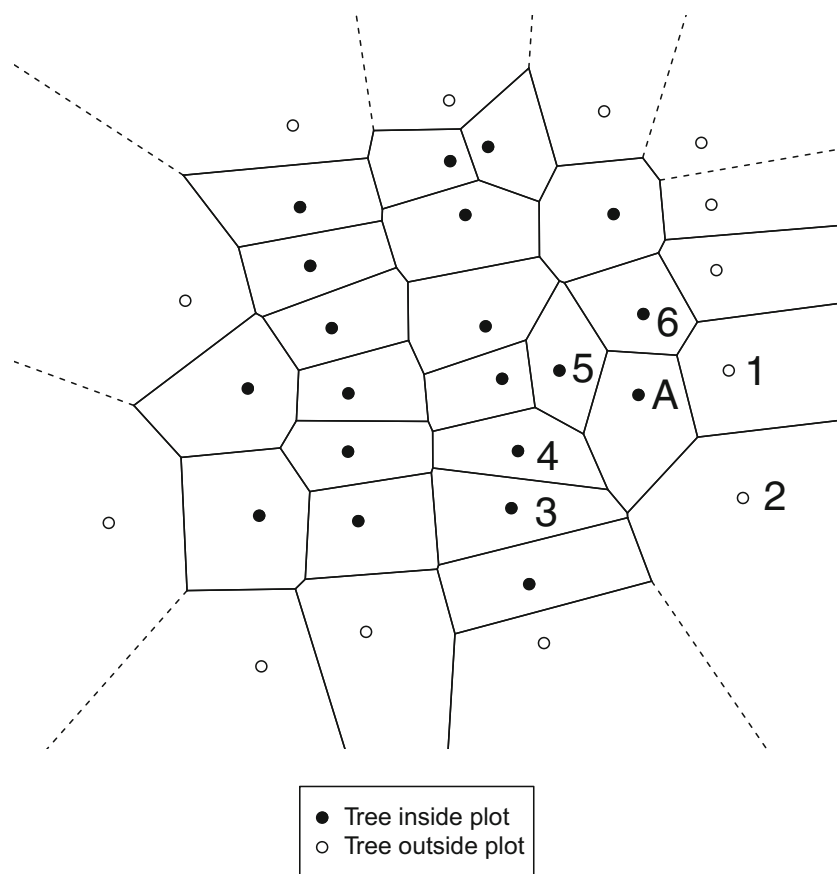

Fig. 2 Voronoi tessilation of plot 4-1. Trees with solid points correspond to trees within the plot, while trees with open points correspond to competitor trees outside the plot that were measured. Tree $A$ has trees 1 to 6 as competitors, where trees 1 and 2 are trees outside the plot

- $g\left(\mathrm{SI}_{i j}\right)$ is the site effect (see site effect section below).

- $h\left(\mathrm{DBH}_{i j k}\right)$ is the size effect (see size effect section below).

- $u_{k}$ is the plantation random effect, where $u_{k} \sim N\left(0, \sigma_{k}^{2}\right)$.

- $\quad v_{j k}$ is the plot within the plantation random effect, where $v_{j k} \sim N\left(0, \sigma_{j k}^{2}\right)$.

- $i, j$ and $k$ are indices representing respectively the tree, plot and plantation.

- $\quad e$ is the residual error, where $e \sim N\left(0, g(\mathrm{DBH}) \sigma^{2}\right)$ and $g(\mathrm{DBH})=|\mathrm{DBH}|^{\delta}$ in order to account for the observed heteroscedasticity.

For the additive models (Eq. 2), the natural logarithm of the DBH was used in order to describe the curvilinear relationship between RBAI and DBH. All possible combinations of the linear terms were tested. Each competition index presented in Table 2 was subsequently compared. In all, seven combinations were tested for each species.

For the nonlinear models, the different components of the model are defined as follows.

Site effect The site effect was assumed to be linear with site index, after visual inspection of the data

$g\left(S I_{i j}\right)=\left(b_{31}+b_{32} \mathrm{SI}_{i j}\right)$

where $b_{31}$ and $b_{32}$ are fixed effect parameters estimated by the regression.
Size effect Size effect is the change in RBAI with the size of the tree. The effect of target tree on RBAI was modelled with a lognormal function (Canham et al. 2006).

$h\left(\mathrm{DBH}_{i j k}\right)=e^{-0.5 \frac{\ln \left(\mathrm{DBH}_{i j k} / b_{33}\right)^{2}}{b_{34}}}$

Both parameters are fixed effects estimated by the regression. For all the nonlinear models except for the one using the clade-separated BAL, $b_{34}$ was set to 1 in order to obtain model convergence.

Competition effect The competition effect is the reduction in RBAI of a tree due to the competition exerted on a tree. The RBAI of a target tree is assumed to decrease with an increase in competition. It is defined using the negative exponential function proposed by Canham et al. (2006) for the nonlinear models (Eq. 3) whereas the linear models use $f\left(\mathrm{CI}_{i j k}\right)$

$f\left(\mathrm{CI}_{i j k}\right)=e^{\left(f\left(\mathrm{CI}_{i j k}\right)\right)^{b 36}}$

$f\left(\mathrm{CI}_{i j k}\right)=f\left(\mathrm{CI}_{i j k}\right)$

The fixed effect parameter $b_{36}$ was either estimated by the regression or set to 1 in order to obtain model convergence for the models using the pooled MEI for the other conifers and the pooled BAL for balsam fir, other conifers and broadleaves.

Finally, both the pooled and clade-separated competition indices were tested. The competition effect was thus expressed as $f\left(\mathrm{CI}_{i j k}\right)=b_{23} \cdot \mathrm{CI}_{\text {pooled } i j k}$ for the linear models and $f\left(\mathrm{CI}_{i j k}\right)=-b_{35} \cdot \mathrm{CI}_{\text {pooled } i j k}$ for the nonlinear models, where $b_{23}$ and $b_{35}$ are fixed effect parameters estimated by the regression and $\mathrm{CI}_{\text {pooled } i j k}$, the pooled competition index. For the clade-separated competition indices, $f\left(\mathrm{CI}_{i j k}\right)$ was expressed as $f\left(\mathrm{CI}_{i j k}\right)=b_{24} \cdot \mathrm{CI}_{B i j k}+b_{25} \cdot \mathrm{CI}_{C i j k}$ for the linear models and as $f\left(\mathrm{CI}_{i j k}\right)=-\left(b_{37} \cdot \mathrm{CI}_{B i j k}+b_{38} \cdot \mathrm{CI}_{F i j k}\right)$ for the nonlinear models, where $\mathrm{CI}_{B i j k}$ and $\mathrm{CI}_{F i j k}$ are the competition indices calculated from broadleaf or conifer competition, respectively, and $b_{24}$, $b_{25}, b_{37}$ and $b_{38}$ fixed effect parameters were estimated by the regression. We will hereafter refer to the pooled competition index or the clade competition index to distinguish between these two methods for quantifying the competition around a given target tree.

Models were calibrated with the 'nlme' package in $\mathrm{R}$ (Pinheiro et al. 2015). Akaike's information criterion (AIC) was used for model comparison (Pinheiro and Bates 2000). Model evaluation was also carried out through inspection of the residuals versus the predicted values and the different variables used in the models. Normality and homoscedasticity were checked visually. 


\section{Results}

For all species and mathematical forms, the best distanceindependent competition index was the BAL (at least 100 AIC points difference, not shown) while the best distancedependent competition index was the MEI (at least 60 AIC points difference, not shown). The pooled competition index was always better than the clade competition index for the linear models (Table 3). In the case of the nonlinear models, the pooled competition index also had the lowest AIC except for white spruce for which the best AIC was obtained for the clade competition index. Furthermore, the nonlinear models generally had the lowest AIC. These results are supported by plots of the residuals, where trends can be observed for the linear models and not for the nonlinear ones (Figs. 3 and 4).

\subsection{Parameter estimates of linear models}

The parameters associated to the site index $\left(b_{01}\right)$ were found to be significantly positive for white spruce and broadleaves (Tables 4, 5, 6 and 7). However, for the other species (i.e. balsam fir and other conifers), site index was not found to have a significant effect on the RBAI. The parameters associated to $\mathrm{DBH}\left(b_{22}\right)$ were found to be significantly negative for all models constructed and for all species (Tables 4, 5, 6 and 7).

For the pooled competition indices $\left(b_{23}\right)$, MEI and BAL were found to be negatively related to white spruce and balsam fir RBAI (Tables 4 and 5 ). The parameter estimate associated to broadleaved competition was greater $\left(b_{24}=-0.162\right.$ for MEI, $b_{24}=-0.0030$ for BAL) than the parameter estimate associated to coniferous competition $\left(b_{24}=-0.143\right.$ for MEI, $b_{24}=-0.0010$ for BAL), when clade competition indices was used for white spruce. Such a difference was also observed for balsam fir when the MEI is used (Table 7).

\subsection{Parameter estimates of nonlinear models}

The nonlinear models evidenced that white spruce RBAI was always proportional to site index $\left(b_{32}\right)$ while balsam fir RBAI was never found to vary with site index (Tables $8,9,10$ and 11). Furthermore, RBAI was found to decrease with DBH for all species (Fig. 5). RBAI was also found to decrease with increasing competition when using either MEI (Table 8) or BAL (Table 9). As with the linear models, the clade competition indices (Tables 10 and 11) revealed that broadleaves competition ( $b_{37}=1.4262$ for MEI, $b_{37}=0.3326$ for BAL) is more important than coniferous competition $\left(b_{39}=0.8886\right.$ for MEI, $b_{39}=0.0457$ for BAL) for white spruce. The same trend was observed in the case of the balsam fir $\left(b_{37}=0.9996\right.$ for MEI, $b_{37}=0.1321$ for BAL versus $b_{39}=0.9020$ for MEI, $b_{39}=0.0798$ for $\left.\mathrm{BAL}\right)$.

\section{Discussion}

Our results demonstrated that nonlinear models had better fit statistics than linear models for all species. The discussion will, however, focus on white spruce $(n=1048)$ and balsam fir $(n=365)$, as the number of trees of the two remaining species groups ( $n=175$ for other conifers and $n=110$ for broadleaves) is too small. The best competition index varies between species and model forms. Indeed, for white spruce, the best competition index was the BAL in the nonlinear form and MEI in the linear form. Moreover, we were able to demonstrate that white spruce growth is more negatively affected by broadleaved competition than from conifer competition.

White spruce and balsam fir are coniferous species with similar productivities (Burns et al. 1990). Their shade tolerances are, however, slightly different, as balsam fir is shadetolerant and white spruce is intermediate (Humbert et al. 2007). Most of the present broadleaved species are both
Table 3 Akaike's information criterion (AIC) for the null, linear and nonlinear models

\begin{tabular}{|c|c|c|c|c|c|}
\hline & & White spruce & Balsam fir & Other conifers & Broadleaves \\
\hline \multicolumn{6}{|c|}{ Null model } \\
\hline & & -5310.0 & -1486.4 & -884.7 & -368.6 \\
\hline \multicolumn{6}{|c|}{ Linear models } \\
\hline \multirow[t]{2}{*}{ MEI } & Pooled competition index & -5449.7 & -1561.1 & -874.3 & -376.7 \\
\hline & Clade competition index & -5438.7 & -1552.6 & -875.2 & -376.7 \\
\hline \multirow[t]{2}{*}{ BAL } & Pooled competition index & -5411.5 & -1519.0 & -875.6 & -367.8 \\
\hline & Clade competition index & -5402.2 & -1526.3 & -875.3 & -366.5 \\
\hline \multicolumn{6}{|c|}{ Nonlinear mixed models } \\
\hline \multirow[t]{2}{*}{ MEI } & Pooled competition index & -5523.2 & -1623.1 & -937.4 & -396.0 \\
\hline & Clade competition index & -5515.5 & -1608.3 & -939.2 & -394.2 \\
\hline \multirow[t]{2}{*}{ BAL } & Pooled competition index & -5526.8 & -1602.4 & -950.0 & -398.7 \\
\hline & Clade competition index & -5539.1 & -1601.4 & -949.0 & -397.2 \\
\hline
\end{tabular}

Lowest AIC for each species and mathematical forms are in italics 
Fig. 3 Residuals against predicted values for linear and nonlinear growth models where the effect of conifers and broadleaves is discriminated. First and second rows are the linear models (with BAL: a-d; with Martin-Ek: e-h). Second and third rows are the nonlinear models (with BAL: i-l; with Martin-Ek: $\mathbf{m}-\mathbf{p})$. White spruce is in the first column (a, e, $\mathbf{i}, \mathbf{m})$, balsam fir in the second column $(\mathbf{b}, \mathbf{f}, \mathbf{j}, \mathbf{n})$, other conifers in the third $(\mathbf{c}, \mathbf{g}, \mathbf{k}, \mathbf{o})$ and broadleaves in the forth $(\mathbf{d}, \mathbf{h}, \mathbf{l}, \mathbf{p})$
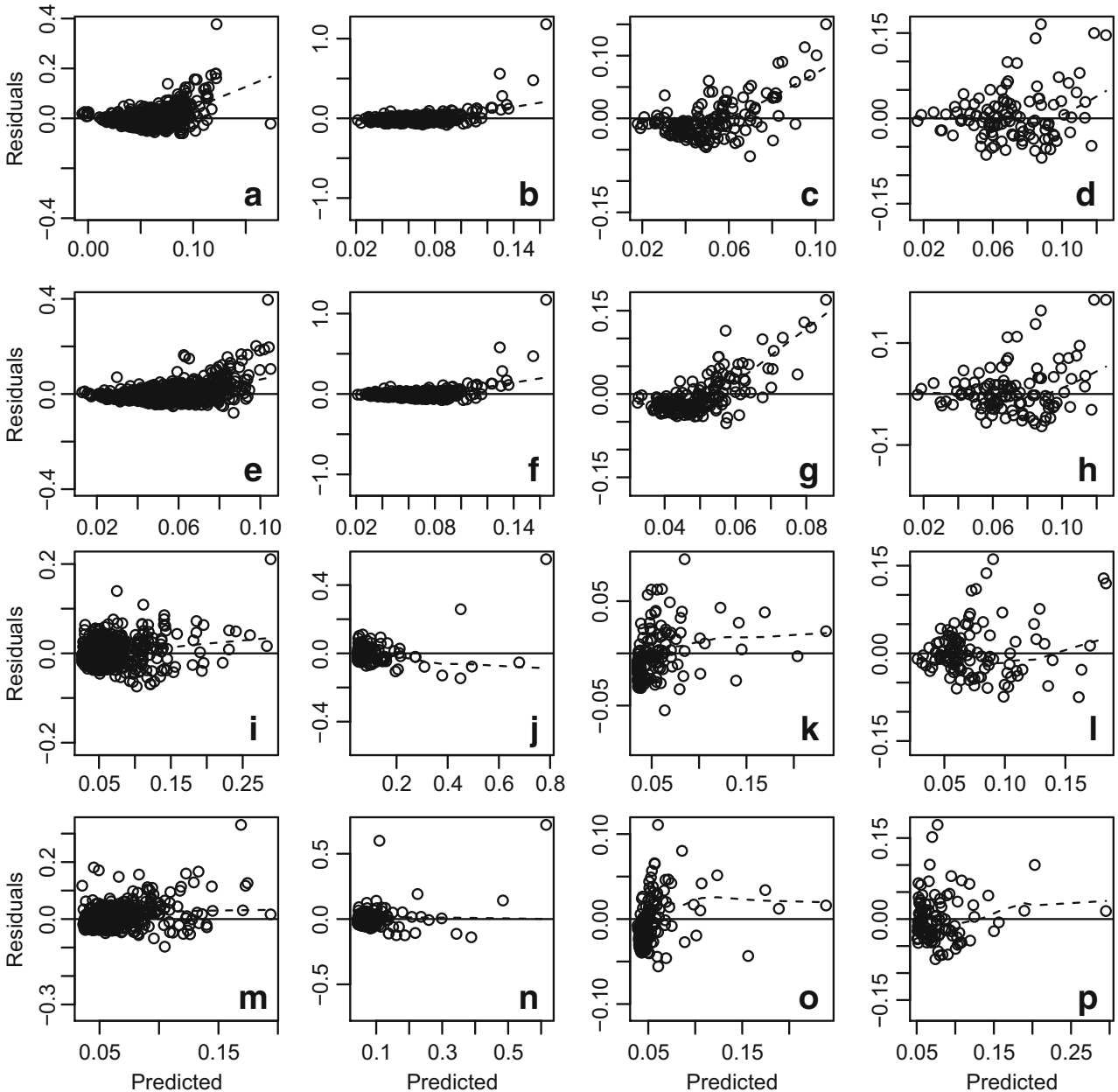

pioneer species and shade intolerant (Humbert et al. 2007), thus showing strong juvenile growth (Franceschini and Schneider 2014). Grouping the coniferous and broadleaved species to quantify competition is thus relevant, given our data.

For all species, nonlinear models had lower AIC values than linear models. Indeed, nonlinear models are more flexible than the linear models, even when the transformation of the predictor variables in the linear models was tested. The nonlinear model was designed to represent the observed relative growth trend (Canham et al. 2006). This model structure takes into account the important variables influencing tree growth, such as site index, tree size and competition. Moreover, although they are mathematically more complex than linear models, they are more biologically meaningful.

Individual tree relative basal increment was chosen over basal increment for several reasons. Preliminary analyses showed that the effects of competition on tree growth were better identified when RBAI was used (not shown). This is consistent with previous studies that found that relative basal area growth better quantifies the effects of competition (Larocque and Marshall 1993; Larocque 2002). As the scope of the present work was not to compare RBAI to absolute basal area increment, a formal differentiation was not undertaken.

It is well known that diameter growth is highest for small trees and declines to an asymptote with increasing tree size as the wood is distributed over a larger area (Canham et al. 2006). This was also observed for RBAI in the present work. Our formulation of the nonlinear model included an additional intercept, when compared to the formulation proposed by Canham et al. (2006). This intercept corresponds to the relative growth of a very large tree. In other words, the minimum relative growth for a large white spruce varies between 0.0255 and 0.0365 , depending on the model.

There was a large between-plantation variability in environmental factors even if the sampling area was restricted to a region of Eastern Quebec. This variability was quantified using the site index. White spruce relative growth was thus found to increase with site quality (SI) in accordance with previous results (Canham et al. 2006; Prégent et al. 2010). Balsam fir growth was, however, not related to site index in our models. The calculated SI is that of white spruce and used in the balsam fir models, as a 
Fig. 4 Residuals against predicted values for linear and nonlinear relative growth models where the effect of conifers and broadleaves is not discriminated. First and second rows are the linear models (with BAL: a-d; with Martin-Ek: e-h). Second and third rows are the nonlinear models (with BAL: $\mathbf{i}-\mathbf{l}$; with Martin-Ek: $\mathbf{m}-\mathbf{p})$. White spruce is in the first column $(\mathbf{a}, \mathbf{e}, \mathbf{i}, \mathbf{m})$ balsam fir in the second column $(\mathbf{b}, \mathbf{f}, \mathbf{j}, \mathbf{n})$, other conifers in the third $(\mathbf{c}, \mathbf{g}, \mathbf{k}, \mathbf{o})$ and broadleaves in the forth $(\mathbf{d}, \mathbf{h}, \mathbf{l}, \mathbf{p})$
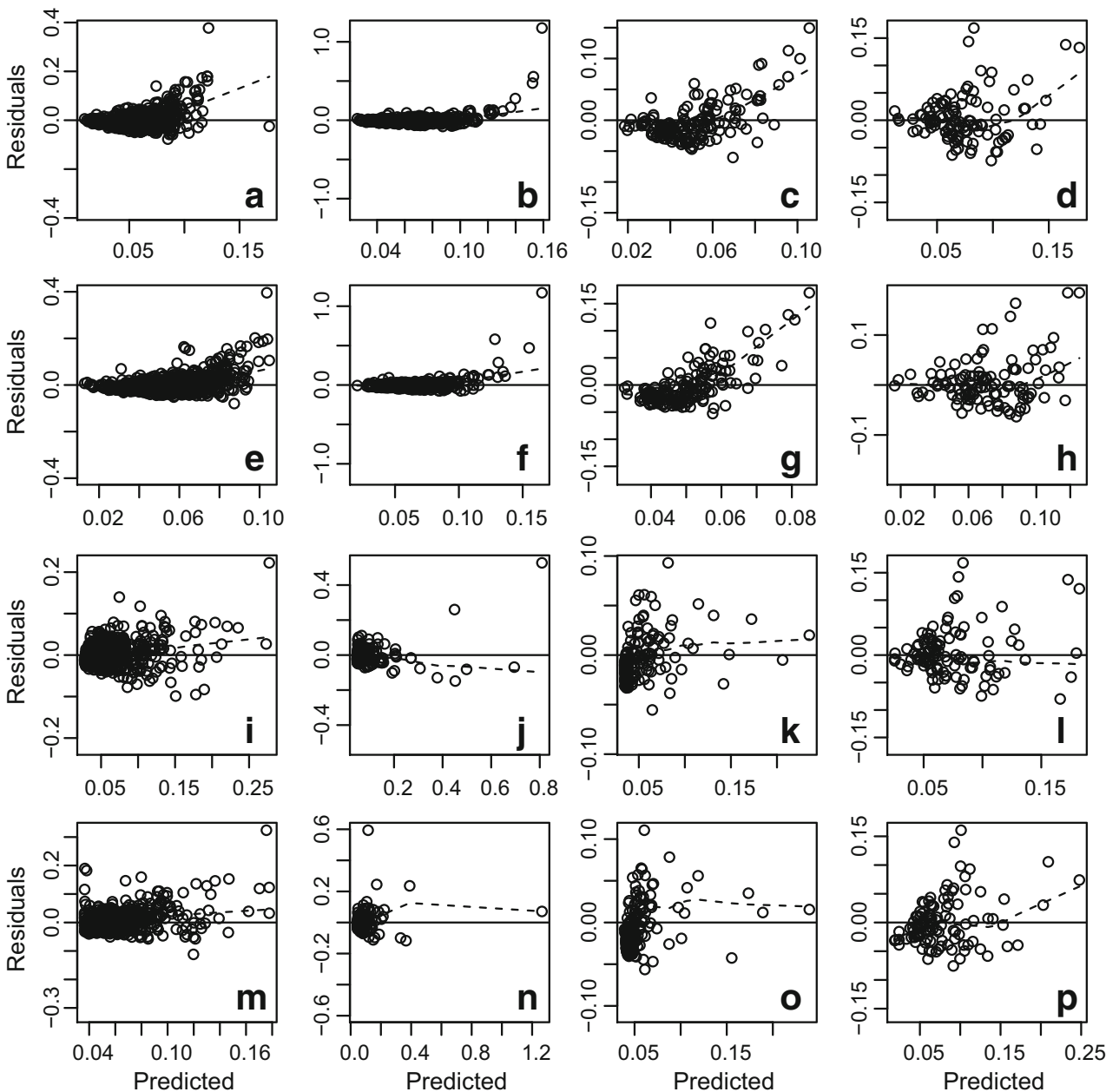

specific balsam fir SI could not be estimated. This result refutes our assumption that balsam fir SI is highly correlated to white spruce SI. Balsam fir was naturally regenerated and thus found in all of the social classes (from understory to dominant). Consequently, it is likely that other factors such as competition might be more important.

Table 4 Parameter estimation (standard errors in parentheses) for linear RBAI models using the pooled MEI competition index as described in Eq. 2

\begin{tabular}{|c|c|c|c|c|c|}
\hline & Parameters & White spruce & Balsam fir & Other conifers & Broadleaves \\
\hline \multirow[t]{4}{*}{ Fixed part } & $b_{20}$ & $0.1517(0.0204)$ & $0.2629(0.0191)$ & $0.1470(0.0238)$ & $0.0687(0.0410)$ \\
\hline & $b_{21}$ & $0.0043(0.0015)$ & n.s. & n.s. & $0.0111(0.0028)$ \\
\hline & $b_{22}$ & $-0.0278(0.0021)$ & $-0.0389(0.0036)$ & $-0.0184(0.0044)$ & $-0.0280(0.0056)$ \\
\hline & $b_{23}$ & $-0.0144(0.0013)$ & $-0.0155(0.0021)$ & $-0.0096(0.0028)$ & n.s. \\
\hline \multirow[t]{4}{*}{ Random effects } & $\sigma_{j k}^{\mathrm{a}}$ & 0.0158 & 0.0090 & 0.0208 & 0.0000 \\
\hline & $\sigma_{k}^{\mathrm{b}}$ & 0.0107 & 0.0111 & 0.0064 & 0.0178 \\
\hline & $\sigma^{2 \mathrm{c}}$ & 4.4560 & 4.9708 & 3.3294 & 4.5534 \\
\hline & $\delta^{\mathrm{d}}$ & -1.2252 & -1.1848 & -1.1889 & -1.1880 \\
\hline
\end{tabular}

n.s. not significant parameter $(p$ value $>0.05)$

a Plot random effect standard deviation

${ }^{\mathrm{b}}$ Plantation random effect standard deviation

${ }^{\mathrm{c}}$ Residual variance

${ }^{\mathrm{d}}$ Variation function parameter estimate 
Table 5 Parameter estimation (standard errors in parentheses) for linear RBAI models using the pooled BAL competition index as described in Eq. 2

\begin{tabular}{llllll}
\hline & Parameters & White spruce & Balsam fir & Other conifers & Broadleaves \\
\hline Fixed part & $b_{20}$ & $0.2206(0.0217)$ & $0.2715(0.0229)$ & $0.2304(0.0356)$ & $0.1924(0.0602)$ \\
& $b_{21}$ & $0.0046(0.0013)$ & n.s. & n.s. & $0.0110(0.0030)$ \\
& $b_{22}$ & $-0.0439(0.0032)$ & $-0.0426(0.0045)$ & $-0.0357(0.0069)$ & $-0.0500(0.0093)$ \\
Random effects & $b_{23}^{\mathrm{a}}$ & $-0.0010(0.0001)$ & $-0.0008(0.0002)$ & $-0.0010(0.0002)$ & $-0.0014(0.0005)$ \\
& $\sigma_{j k}^{\mathrm{a}}$ & 0.0124 & 0.0129 & 0.0176 & 0.0085 \\
& $\sigma_{k}^{\mathrm{b}}$ & 0.0104 & 0.0000 & 0.0072 & 0.0164 \\
& $\sigma^{2 \mathrm{c}}$ & 4.1129 & 4.7621 & -1.5362 & 2.0249 \\
& $\delta^{\mathrm{d}}$ & -1.2021 & -1.1570 & -1.2048 & -0.9985 \\
\hline
\end{tabular}

n.s. not significant parameter $(p$ value $>0.05$ )

${ }^{a}$ Plot random effect standard deviation

${ }^{\mathrm{b}}$ Plantation random effect standard deviation

${ }^{\mathrm{c}}$ Residual variance

${ }^{\mathrm{d}}$ Variation function parameter estimate

The dominant and codominant cover was composed mainly by the planted white spruce. The stands were even-aged and the within-stand spatial variability low, explaining why DIC performed better in the white spruce RBAI models (Prévosto 2005; Boivin et al. 2010). In the case of balsam fir, the MEI was found to be the best competition index. As balsam fir was ingrown, one could argue that the competition exerted on balsam fir was more varied and thus similar to that what is observed in mixed and/or heterogeneous stands. It was therefore expected that better fit statistics would be obtained using DDC as they integrate the structural variation within the stand (Pretzsch 2009). Furthermore, such indices should be better when the objective is to simulate innovative thinnings in order to convert even-aged stands into uneven-aged ones (Boivin et al. 2010).

The effect of the conifer and broadleaved competition on tree growth differs according to the target tree species. Indeed, the reduction in white spruce relative growth is more important when the competitors are broadleaves than when they are conifers. For balsam fir, even though deciduous competition reduces growth more than coniferous competition, model comparison using the AIC indicates that distinguishing competitor clades does not improve the model. This is in accordance with previous results which demonstrated that balsam fir was poorly affected by hardwood (especially trembling aspen) competition (Boivin et al. 2010). Balsam fir is known

Table 6 Parameter estimation (standard errors in parentheses) for linear RBAI models using MEI where competition effect is discriminated as described in Eq. 2

\begin{tabular}{llllll}
\hline & Parameters & White spruce & Balsam fir & Other conifers & Broadleaves \\
\hline Fixed part & $b_{20}$ & $0.1523(0.0203)$ & $0.2623(0.0191)$ & $0.1493(0.0236)$ & $0.0687(0.0410)$ \\
& $b_{21}$ & $0.0043(0.0015)$ & n.s. & n.s. & $0.0111(0.0028)$ \\
& $b_{22}$ & $-0.0279(0.0021)$ & $-0.0388(0.0036)$ & $-0.0188(0.0044)$ & $-0.0280(0.0056)$ \\
& $b_{24}$ & $-0.0162(0.0039)$ & $-0.0231(0.0059)$ & n.s. & n.s. \\
Random effects. & $-0.0143(0.0013)$ & $-0.0149(0.0021)$ & $-0.0099(0.0027)$ & 0.0000 \\
& $b_{25}$ & 0.0157 & 0.0094 & 0.0205 & 0.0178 \\
& $\sigma_{j k}^{\mathrm{a}}$ & 0.0107 & 0.0109 & 3.0063 & 4.5534 \\
& $\sigma_{k}^{\mathrm{b}}$ & 4.4393 & 5.1239 & -1.1840 & -1.1880 \\
\hline
\end{tabular}

n.s. not significant parameter ( $p$ value $>0.05$ )

${ }^{a}$ Plot random effect standard deviation

${ }^{\mathrm{b}}$ Plantation random effect standard deviation

${ }^{\mathrm{c}}$ Residual variance

${ }^{\mathrm{d}}$ Variation function parameter estimate 
Table 7 Parameter estimation (standard errors in parentheses) for linear RBAI models using BAL index where competition effect is discriminated as described in Eq. 2

\begin{tabular}{llllll}
\hline & Parameters & White spruce & Balsam fir & Other conifers & Broadleaves \\
\hline Fixed part & $b_{20}$ & $0.2241(0.0219)$ & $0.2612(0.0231)$ & $0.2294(0.0357)$ & $0.1536(0.0570)$ \\
& $b_{21}$ & $0.0045(0.0013)$ & n.s. & n.s. & $0.0112(0.0031)$ \\
& $b_{22}$ & $-0.0441(0.0032)$ & $-0.0407(0.0045)$ & $-0.0356(0.0069)$ & $-0.0428(0.0083)$ \\
& $b_{24}$ & $-0.0030(0.0009)$ & n.s. & n.s. & n.s. \\
Random effects & $b_{25}$ & $-0.0010(0.0001)$ & $-0.0007(0.0002)$ & $-0.0010(0.0002)$ & $-0.0013(0.0006)$ \\
& $\sigma_{j k}^{\mathrm{a}}$ & 0.0122 & 0.0103 & 0.0179 & 0.0104 \\
& $\sigma_{k}^{\mathrm{b}}$ & 0.0111 & 0.0097 & 0.0071 & 0.0169 \\
& $\sigma^{2 \mathrm{c}}$ & 4.0353 & 5.3915 & 3.4848 & -1.2015 \\
& $\delta^{\mathrm{d}}$ & -1.1990 & -1.1922 & & -1.1002 \\
\hline
\end{tabular}

n.s. not significant parameter $(p$ value $>0.05)$

${ }^{a}$ Plot random effect standard deviation

${ }^{\mathrm{b}}$ Plantation random effect standard deviation

${ }^{\mathrm{c}}$ Residual variance

${ }^{\mathrm{d}}$ Variation function parameter estimate

to be a very shade-tolerant species while white spruce is less shade-tolerant (Humbert et al. 2007). Canham et al. (2006) demonstrated that shade-tolerant trees are less sensitive to competition which may be related to the observed insensitivity of balsam fir to competitor species.

Our results indicate that broadleaves have a stronger effect on white spruce growth and, to a lesser extent, balsam fir. This may be related to the fact that broadleaves have larger crown radii (Millet 2012) and thus exert more competition than conifers (Canham et al. 2006; Dieler and Pretzsch 2013). The main broadleaved species (e.g. white birch and trembling aspen) have stronger juvenile height growth (Franceschini and Schneider 2014) and are likely to be in the same social class as the dominant white spruce trees. Confirming this interpretation would require to take into account the light availability and light use efficiency in the model. This could be achieved by using light-tracing algorithms (Groot et al. 2014) with light extinction coefficients (Duursma et al. 2010). Another way to confirm this interpretation would be to separate competition species by species and not only by clade in order to quantify

Table 8 Parameter estimation (standard errors in parentheses) for nonlinear RBAI models using the pooled MEI competition index as described in Eq. 3

\begin{tabular}{|c|c|c|c|c|c|}
\hline & Parameters & White spruce & Balsam fir & Other Conifers & Broadleaves \\
\hline \multirow[t]{7}{*}{ Fixed part } & $b_{30}$ & $0.0365(0.0031)$ & $0.0426(0.0034)$ & $0.0387(0.0063)$ & $0.0444(0.0078)$ \\
\hline & $b_{31}$ & $-0.0342(0.0673)$ & $2.4850(1.4347)$ & $0.3785(0.1520)$ & $-0.2996(0.2455)$ \\
\hline & $b_{32}$ & $0.0184(0.0072)$ & n.s. & n.s. & $0.0447(0.0306)$ \\
\hline & $b_{33}$ & $-15.5588(2.3740)$ & $-12.8471(1.7331)$ & $-9.8028(2.7813)$ & $-8.8537(3.9482)$ \\
\hline & $b_{34}$ & $1^{\mathrm{e}}$ & $1^{\mathrm{e}}$ & $1^{\mathrm{e}}$ & $1^{\mathrm{e}}$ \\
\hline & $b_{35}$ & $0.5435(0.1143)$ & $2.8134(0.6927)$ & $0.8016(0.1719)$ & n.s. \\
\hline & $b_{36}$ & $2.1027(0.4353)$ & $0.2607(0.0912)$ & $1^{\mathrm{e}}$ & n.s. \\
\hline \multirow[t]{4}{*}{ Random effects } & $\sigma_{j k}^{\mathrm{a}}$ & 0.0153 & 0.0146 & 0.0213 & 0.0202 \\
\hline & $\sigma_{k}^{\mathrm{b}}$ & 0.0095 & $\mathrm{x}$ & $\mathrm{x}$ & $\mathrm{x}$ \\
\hline & $\sigma^{2 \mathrm{c}}$ & 4.5746 & 1.8034 & 1.3459 & 1.4208 \\
\hline & $\delta^{\mathrm{d}}$ & -1.2340 & -0.9661 & -1.0103 & -0.8980 \\
\hline
\end{tabular}

n.s. not significant parameter ( $p$ value $>0.05$ )

${ }^{a}$ Plot random effect standard deviation

${ }^{\mathrm{b}}$ Plantation random effect standard deviation

${ }^{\mathrm{c}}$ Residual variance

${ }^{\mathrm{d}}$ Variation function parameter estimate

${ }^{\text {e }}$ Fixed value to 1 (e.g. not estimated by the regression) 
Table 9 Parameter estimation (standard errors in parentheses) for nonlinear RBAI models using the pooled BAL competition index as described in Eq. 3

\begin{tabular}{|c|c|c|c|c|c|}
\hline & Parameters & White spruce & Balsam fir & Other conifers & Broadleaves \\
\hline \multirow[t]{7}{*}{ Fixed part } & $b_{30}$ & $0.0255(0.0029)$ & $0.0487(0.0032)$ & $0.0336(0.0064)$ & $0.0179(0.0132)$ \\
\hline & $b_{31}$ & $-0.1302(0.0972)$ & $2.0527(0.4851)$ & $-0.9071(0.8982)$ & $-0.1552(0.0933)$ \\
\hline & $b_{32}$ & $0.0438(0.0115)$ & n.s. & $0.1718(0.1238)$ & $0.0265(0.0089)$ \\
\hline & $b_{33}$ & $-14.1059(1.5029)$ & $-4.8198(0.6377)$ & $-8.0235(2.1179)$ & $-28.2363(6.9015)$ \\
\hline & $b_{34}$ & $1^{\mathrm{e}}$ & $1^{\mathrm{e}}$ & $1^{\mathrm{e}}$ & $1^{\mathrm{e}}$ \\
\hline & $b_{35}$ & $0.0444(0.0174)$ & $0.0840(0.0162)$ & $0.0656(0.0119)$ & $0.0238(0.0093)$ \\
\hline & $b_{36}$ & $1.0997(0.1250)$ & $1^{\mathrm{e}}$ & $1^{\mathrm{e}}$ & $1^{\mathrm{e}}$ \\
\hline \multirow[t]{4}{*}{ Random effects } & $\sigma_{j k}^{\mathrm{a}}$ & 0.0079 & 0.0149 & 0.0193 & 0.0140 \\
\hline & $\sigma_{k}^{\mathrm{b}}$ & 0.0088 & $\mathrm{x}$ & $\mathrm{x}$ & $\mathrm{x}$ \\
\hline & $\sigma^{2 \mathrm{c}}$ & 2.5953 & 1.2201 & 0.6286 & 2.6173 \\
\hline & $\delta^{\mathrm{d}}$ & -1.1059 & -0.8714 & -0.8495 & -1.0421 \\
\hline
\end{tabular}

n.s. not significant parameter $(p$ value $>0.05)$

${ }^{\text {a }}$ Plot random effect standard deviation

${ }^{\mathrm{b}}$ Plantation random effect standard deviation

${ }^{\mathrm{c}}$ Residual variance

${ }^{\mathrm{d}}$ Variation function parameter estimate

${ }^{\mathrm{e}}$ Fixed value to 1 (e.g. not estimated by the regression)

the effects of intra-specific competition versus inter-specific competition. This could not be undertaken with our dataset as there were a limited number of trees for certain species.

In the province of Quebec, ecosystem-based management must now be carried out, even in plantations (Barrette et al.
2014). This has brought forest managers to propose, among other things, new thinning methods such as selective thinning (Gagné et al. 2016). The final objective of this type of thinning is to convert the stands into uneven-aged/irregular structures (Schütz 2001; Schütz 2002). Moreover, the stand structure is

Table 10 Parameter estimation (standard errors in parentheses) for nonlinear RBAI models using MEI index where competition effect is discriminated as described in Eq. 3

\begin{tabular}{|c|c|c|c|c|c|}
\hline & Parameters & White spruce & Balsam fir & Other conifers & Broadleaves \\
\hline \multirow[t]{9}{*}{ Fixed part } & $b_{30}$ & $0.0350(0.0031)$ & $0.0431(0.0032)$ & $0.0381(0.0062)$ & $0.0510(0.0076)$ \\
\hline & $b_{31}$ & $-0.0545(0.0776)$ & $0.5828(0.1155)$ & $0.3629(0.1363)$ & $1.2712(1.4528)$ \\
\hline & $b_{32}$ & $0.0225(0.0083)$ & n.s. & n.s. & n.s. \\
\hline & $b_{33}$ & $-18.0355(2.5395)$ & $10.4629(1.3265)$ & $-10.2557(2.7621)$ & 3.1874 (1.5634) \\
\hline & $b_{34}$ & $1^{\mathrm{e}}$ & $1^{\mathrm{e}}$ & $1^{\mathrm{e}}$ & $1^{\mathrm{e}}$ \\
\hline & $b_{37}$ & $1.4262(0.4141)$ & $0.9568(0.3652)$ & n.s. & n.s. \\
\hline & $b_{38}$ & $1^{\mathrm{e}}$ & $1^{\mathrm{e}}$ & n.s. & n.s. \\
\hline & $b_{39}$ & $0.8886(0.1014)$ & $0.9020(0.1273)$ & $0.8211(0.1710)$ & n.s. \\
\hline & $b_{40}$ & $1^{\mathrm{e}}$ & $1^{\mathrm{e}}$ & $1^{\mathrm{e}}$ & n.s. \\
\hline \multirow[t]{4}{*}{ Random effects } & $\sigma_{j k}^{\mathrm{a}}$ & 0.0146 & 0.0139 & 0.0208 & 0.0242 \\
\hline & $\sigma_{k}^{\mathrm{b}}$ & 0.0094 & $\mathrm{x}$ & $\mathrm{x}$ & $\mathrm{x}$ \\
\hline & $\sigma^{2 \mathrm{c}}$ & 4.4431 & 2.7921 & 1.3400 & 1.2093 \\
\hline & $\delta^{\mathrm{d}}$ & -1.2263 & -1.0582 & -1.0101 & -0.8599 \\
\hline
\end{tabular}

n.s. not significant parameter ( $p$ value $>0.05$ )

${ }^{\text {a }}$ Plot random effect standard deviation

${ }^{\mathrm{b}}$ Plantation random effect standard deviation

${ }^{\mathrm{c}}$ Residual variance

${ }^{\mathrm{d}}$ Variation function parameter estimate

${ }^{\mathrm{e}}$ Fixed value to 1 (e.g. not estimated by the regression) 
Table 11 Parameter estimation (standard errors in parentheses) for nonlinear RBAI models using BAL index where competition effect is discriminated as described in Eq. 3

\begin{tabular}{|c|c|c|c|c|c|}
\hline & Parameters & White spruce & Balsam fir & Other conifers & Broadleaves \\
\hline & $b_{30}$ & $0.0265(0.0033)$ & $0.0482(0.0032)$ & $0.0345(0.0064)$ & $0.0277(0.0108)$ \\
\hline & $b_{31}$ & $-0.2801(0.1475)$ & $1.8498(0.4372)$ & $-1.2474(1.1588)$ & $-0.1874(0.1004)$ \\
\hline & $b_{32}$ & $0.0663(0.0237)$ & n.s. & $0.2176(0.1598)$ & $0.0281(0.0104)$ \\
\hline & $b_{33}$ & $-11.1794(5.2466)$ & $-5.0813(0.6626)$ & $-7.4898(2.0537)$ & $-23.3101(6.7866)$ \\
\hline & $b_{34}$ & $1.0504(0.1562)$ & $1^{\mathrm{e}}$ & $1^{\mathrm{e}}$ & $1^{\mathrm{e}}$ \\
\hline & $b_{37}$ & $0.3326(0.0983)$ & $0.1321(0.0598)$ & n.s. & n.s. \\
\hline & $b_{38}$ & $1^{\mathrm{e}}$ & $1^{\mathrm{e}}$ & n.s. & n.s. \\
\hline & $b_{39}$ & $0.0457(0.0192)$ & $0.0798(0.0166)$ & $0.0708(0.0133)$ & $0.0214(0.0118)$ \\
\hline & $b_{40}$ & $1.0826(0.1293)$ & $1^{\mathrm{e}}$ & $1^{\mathrm{e}}$ & $1^{\mathrm{e}}$ \\
\hline \multirow[t]{4}{*}{ Random effects } & $\sigma_{j k}^{\mathrm{a}}$ & 0.0079 & 0.0147 & 0.0196 & 0.0158 \\
\hline & $\sigma_{k}^{\mathrm{b}}$ & 0.0081 & $\mathrm{x}$ & $\mathrm{x}$ & $\mathrm{x}$ \\
\hline & $\sigma^{2 \mathrm{c}}$ & 2.2881 & 1.2738 & 0.6273 & 2.3353 \\
\hline & $\delta^{\mathrm{d}}$ & -1.0795 & -0.8811 & -0.8486 & -1.0156 \\
\hline
\end{tabular}

n.s. not significant parameter ( $p$ value $>0.05$ )

${ }^{\text {a }}$ Plot random effect standard deviation

${ }^{\mathrm{b}}$ Plantation random effect standard deviation

${ }^{\mathrm{c}}$ Residual variance

${ }^{\mathrm{d}}$ Variation function parameter estimate

${ }^{\text {e }}$ Fixed value to 1 (e.g. not estimated by the regression)

Fig. 5 Average relative basal increment as a function of diameter at breast height for each species group modelled
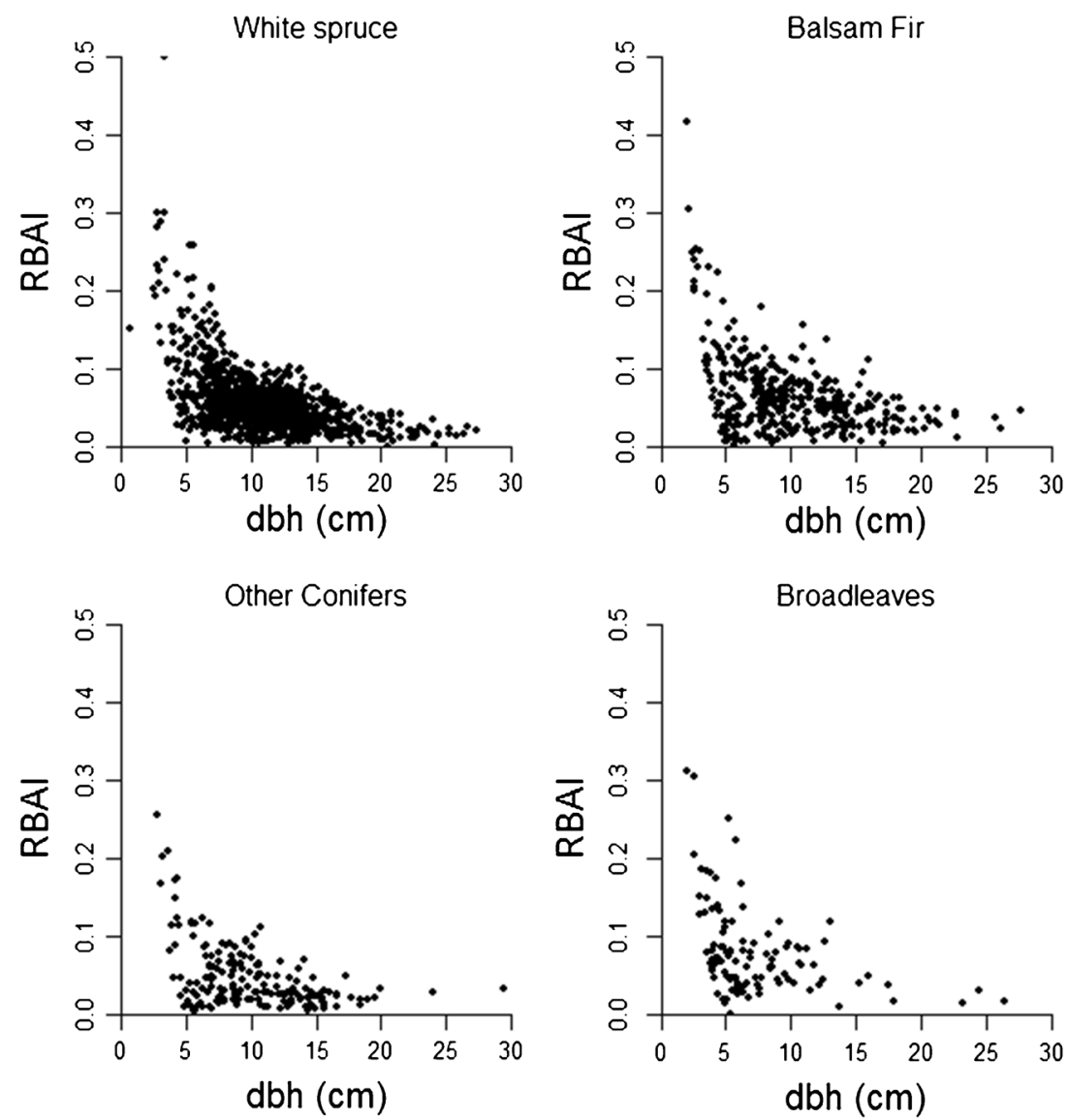

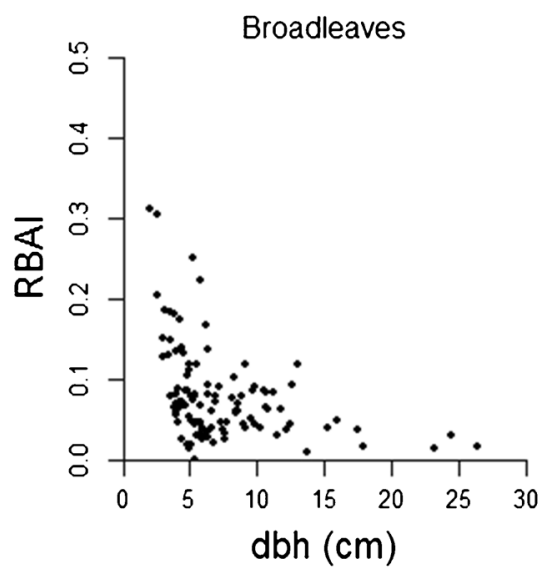


influenced by disturbances. Among them, the most important natural disturbance of these forests is the defoliation of the spruce budworm, which defoliates both balsam fir and white spruce. The effect of defoliation on tree mortality varies, however, by species, with balsam fir having higher mortality rates than white spruce following budworm defoliation (Fortin et al. 2014). Predicting single tree growth in these plantations, with varying complexity due to variations in mortality and thinning types, is thus a challenge. The results presented in this work are a first step in building a growth model for these plantations as it explicitly differentiates the effect of competition on the most important species present in such stands.

\section{Conclusion}

We developed relative basal area increment models at the individual tree level for white spruce and balsam fir growing in Eastern Quebec white spruce plantations with emphasis put on the type of competition. Our results showed that for the planted white spruce, the best competition index was distance-independent as white spruce trees are regularly spaced despite balsam fir and broadleaves ingrowth. Moreover, we demonstrated that white spruce growth is more influenced by broadleaves than by conifers. For the ingrown balsam fir, however, a distancedependent competition index performed better, indicating that stand dynamics in the plantations of Eastern Canada is complex. Such results pave the way to further studies that explicitly separate competition species by species in order to determine which broadleaved species reduces white spruce growth and formulate silvicultural recommendations. Indeed, the growth models we developed will enable forest managers to explore different silviculture options and their effects on tree growth. This would lead to an estimation of stand growth dynamics in the plantations which are being converted towards uneven-aged or irregular structures. This, however, requires additional ingrowth and mortality modules to be developed and field trials to validate the simulations.

Acknowledgements The authors are grateful for the constructive comments made by the two anonymous reviewers, the associate editor and editor-in-chief. The authors would like to thank the Ministère des Forêts, de la Faune et des Parcs of the province of Quebec and the Natural Sciences and Engineering Research Council of Canada for funding. The authors also thank Mélanie Desrochers for preparing the map, as well as Ulysse Rémillard, Olivier Martin, Jérôme Lavoie, Emmanuel CaronGarant, David Grenier-Héon, Laurie Dupont-Leduc and Batistin Bour for their help for the field work, TLS data processing and laboratory work. Finally, the authors would like to thank Luc Gagnon, Luc Lavoie and Laurent Gagné for their help in the first stages of the project.

\section{References}

Barrette M, Leblanc M, Thiffault N et al (2014) Issues and solutions for intensive plantation silviculture in a context of ecosystem management. For Chron 90:748-762. doi:10.5558/tfc2014-147

Boivin F, Paquette A, Papaik MJ et al (2010) Do position and species identity of neighbours matter in 8-15-year-old post harvest mesic stands in the boreal mixedwood? For Ecol Manag 260:1124-1131. doi: $10.1016 /$ j.foreco.2010.06.037

Boucher Y, Arseneault D, Sirois L (2006) Logging-induced change (1930-2002) of a preindustrial landscape at the northern range limit of northern hardwoods, eastern Canada. Can J For Res 36:505-517

Boucher Y, Arseneault D, Sirois L, Blais L (2009) Logging pattern and landscape changes over the last century at the boreal and deciduous forest transition in Eastern Canada. Landsc Ecol 24:171-184. doi: 10.1007/s10980-008-9294-8

Burns RM, Honkala BH (1990) Silvics of North America. Volume 1. Conifers. Agriculture Handbook (Washington) no. 654

Canham CD, Papaik MJ, Uriarte M et al (2006) Neighborhood analyses of canopy tree competition along environmental gradients in New England forests. Ecol Appl 16:540-554

Comeau PG, Wang JR, Letchford T (2003) Influences of paper birch competition on growth of understory white spruce and subalpine fir following spacing. Can J For Res 33:1962-1973

Daniels RF, Burkhart HE, Clason TR (1986) A comparison of competition measures for predicting growth of loblolly pine trees. Can J For Res 16:1230-1237. doi:10.1139/x86-218

Del Degan B (2010) Projet de loi 57 sur l'aménagement durable du territoire forestier. Synthèse des études d'impacts et analyse critique. Del Degan, Massé, Québec, Québec. 16 p. https://www.mffp.gouv. qc.ca/publications/forets/gestion/synthese-etudes-impacts.pdf accessed on Oct. 17th 2016

Dieler J, Pretzsch H (2013) Morphological plasticity of European beech (Fagus sylvatica L.) in pure and mixed-species stands. For Ecol Manag 295:97-108. doi:10.1016/j.foreco.2012.12.049

Duursma RA, Mäkelä A, Reid DEB et al (2010) Self-shading affects allometric scaling in trees. Funct Ecol 24:723-730. doi:10.1111/j. 1365-2435.2010.01690.x

Fortin M, Langevin L (2010) ARTÉMIS-2009: un modèle de croissance basé sur une approche par tiges individuelles pour les forêts du Québec. Mémoire de recherche forestière no. 156. Ministère des Ressources naturelles et de la Faune, Direction de la recherche forestière. Gouvernement du Québec, Québec, Canada

Fortin M, Bédard S, Deblois J (2009) SaMARE: un modèle par tiges individuelles destiné à la prévision de la croissance des érablière de structure inéquienne du Québec méridional. Mémoire de recherche forestière no. 155. Ministère des Ressources naturelles et de la Faune, Direction de la recherche forestière. Gouvernement du Québec, Québec, Canada

Fortin M, Tremblay S, Schneider R (2014) Evaluating a single tree-based growth model for even-aged stands against the maximum size-density relationship: some insights from balsam fir stands in Quebec. Canada For Chron 90:503-515

Franceschini T, Schneider R (2014) Influence of shade tolerance and development stage on the allometry of ten temperate tree species. Oecologia:1-11. doi:10.1007/s00442-014-3050-3

Gagné L, Lavoie L (2014) Rendement des jeunes forêts et potentiel d'éclaircie commerciale dans la forêt publique et la forêt privée du Bas-Saint-Laurent. Conférence Régionale des Élus du Bas-SaintLaurent (CRÉBSL), Québec, Canada

Gagné, Lavoie, Binot (2012) Croissance et propriétés mécaniques du bois après éclaircie commerciale dans une plantation d'épinette blanche (Picea glauca) âgée de 32 ans. Can J For Res 42:291-302. doi:10. 1139/x11-181 
Gagné L, Sirois L, Lavoie L (2016) Comparaison du volume et de la valeur des bois résineux issus d'éclaircies par le bas et par dégagement d'arbres-élites dans l'Est du Canada. Can J For Res 46:1320-1329

Gander W, Golub GH, Strebel R (1994) Fitting of circles and ellipsesleast squares solutions. British J. Math. Computer Sci 4:33-60

Gauthier S, Vaillancourt M-A, Leduc A et al (2008) Aménagement écosystémique en forêt Boréale. Presse de l'Université du Québec, PUQ

Getzin S, Dean C, He F et al (2006) Spatial patterns and competition of tree species in a Douglas-fir chronosequence on Vancouver Island. Ecography 29:671-682

Glover G, Hool J (1979) A basal area ratio predictor of loblolly pine plantation mortality. For. Sci. 25(2): 275-282

Goudiaby V, Brais S, Berninger F, Schneider R (2012) Vertical patterns in specific volume increment along stems of dominant jack pine (Pinus banksiana) and black spruce (Picea mariana) after thinning. Can J For Res 42:733-748. doi:10.1139/x2012-029

Groot A, Adhikary S, Sharma M et al (2014) Effect of species composition on the production rate and efficiency of young Picea glaucaPopulus tremuloides forests. For Ecol Manag 315:1-11

Hegyi F (1974) A simulation model for managing jack-pine stands. Growth models for tree and stand simulation 30: 74-90.

Humbert L, Gagnon D, Kneeshaw D, Messier C (2007) A shade tolerance index for common understory species of northeastern North America. Ecol Indic 7:195-207. doi:10.1016/j.ecolind.2005.12.002

Larocque GR (2002) Examining different concepts for the development of a distance-dependent competition model for red pine diameter growth using long-term stand data differing in initial stand density. For Sci 48:24-34

Larocque GR, Marshall PL (1993) Evaluating the impact of competition using relative growth rate in red pine (Pinus resinosa Ait.) stands. For Ecol Manag 58:65-83. doi:10.1016/0378-1127(93)90132-7

Martin GL, Ek AR (1984) A comparison of competition measures and growth models for predicting plantation red pine diameter and height growth. For. Sci. 30(3): 731-743

Martin E, Kriegel H-P, Sander J, Xu X (1996) A density-based algorithm for discovering clusters in large spatial databases with noise. Kdd 96:226-231

Millet J (2012) L'architecture des arbres des régions tempérées. Multimondes, Québec

Ministère des Forêts, de la Faune et des Parcs (2013) Loi sur l'aménagement durable du territoire forestier. Gouvernement du Québec, Québec

Nyland RD (2003) Even- to uneven-aged: the challenges of conversion. For Ecol Manag 172:291-300. doi:10.1016/S0378-1127(01)00797-6

Othmani A, Piboule A, Krebs M, et al (2011) Towards automated and operational forest inventories with T-Lidar, In 11th International Conference on LiDAR Applications for Assessing Forest Ecosystems (SilviLaser 2011). Hobart, Australia

Pinheiro JC, Bates DM (2000) Mixed-effects models in S and S-PLUS. Springer, New York

Pinheiro J, Bates D, DebRoy S, et al (2015) nlme: linear and nonlinear mixed effects models. https://cran.r-project.org/web/packages/nlme/ index.html accessed on Oct. 17th 2016

Prégent G, Picher G, Auger I (2010) Tarif de cubage, tables de rendement et modèles de croissance pour les plantations d'épinette blanche au Québec. Mémoire de recherche forestière no. 176. Ministère des Forêts, de la Faune et des Parcs, Direction de la recherche forestière. Gouvernement du Québec, Québec, Canada

Pretzsch H (2009) Forest dynamics, growth and yield, springer. Springer Berlin Heidelberg
Pretzsch H, Bielak K, Block J et al (2013) Productivity of mixed versus pure stands of oak (Quercus petraea (Matt.) Liebl. And Quercus robur L.) and European beech (Fagus sylvatica L.) along an ecological gradient. Eur J For Res 132:263-280. doi:10.1007/s10342-0120673-y

Prévosto B (2005) Les indices de compétition en foresterie: exemples d'utilisation, intérêts et limites. Revue forestière française 5:413430

R Development Core Team (2011) R: a language and environment for statistical computing. R Foundation for Statistical Computing. Vienna, Austria. https://www.R-project.org/accessed on October 17 th 2016

Reineke LH (1933) Perfecting a stand-density index for even-aged forests. J Agric Res 46:627-638

Renka RJ, Gebhardt A, Eglen S, et al (2013) tripack: triangulation of irregularly spaced data. R package version 1.3-6. https://CRAN.Rproject.org/package=tripack accessed on Oct. 17th 2016

Robitaille A, Saucier J-P (1998) Paysages régionaux du Québec méridional. Direction de la gestion des stocks forestiers et Direction des relations publiques, Ministère des ressources Naturelles du Québec, Les publications du Québec. Québec

Schneider R, Franceschini T, Fortin M et al (2016) Growth and yield models for predicting tree and stand productivity. In: Ecological forest management handbook. Taylor \& Francis Group/CRC Press. Taylor \& Francis Group/CRC Press, Boca Raton, Florida

Schütz JP (2001) Opportunities and strategies of transforming regular forests to irregular forests. For Ecol Manag 151:87-94

Schütz JP (2002) Silvicultural tools to develop irregular and diverse forest structures. Forestry 75:329-337

Simard SW, Sachs DL, Vyse A, Blevins LL (2004) Paper birch competitive effects vary with conifer tree species and stand age in interior British Columbia forests: implications for reforestation policy and practice. For Ecol Manag 198:55-74

Simard SW, Hagerman SM, Sachs DL et al (2005) Conifer growth, Armillaria ostoyae root disease, and plant diversity responses to broadleaf competition reduction in mixed forests of southern interior British Columbia. Can J For Res 35:843-859

Spurr SH (1962) A measure of point density. For. Sci. 8(1): 85-96

Valladares F, Niinemets Ü (2008) Shade tolerance, a key plant feature of complex nature and consequences. Annu Rev Ecol Evol Syst 39: 237-257. doi:10.1146/annurev.ecolsys.39.110707.173506

Valladares F, Pearcy RW (1998) The functional ecology of shoot architecture in sun and shade plants of Heteromeles arbutifolia M. Roem., a Californian chaparral shrub. Oecologia 114:1-10

Voronoï G (1908) Nouvelles applications des paramètres continus à la théorie des formes quadratiques. Deuxième mémoire Recherches sur les parallélloèdres primitifs Journal für die reine und angewandte Mathematik 134:198-287

Wang JR, Comeau P, Kimmins JP (1995) Simulation of mixedwood management of aspen and white spruce in northeastern British Columbia. Water Air Soil Pollut 82:171-178. doi:10.1007/ BF01182831

Weiskittel AR, Hann DW, Kershaw Jr, JA, Vanclay JK (2011) Forest growth and yield modeling. John Wiley \& Sons. West Sussex

Wykoff WR, Crookston NL, Stage, AR (1982) User's guide to the stand prognosis model. General technical report INT-133. S Department of Agriculture, Forest Service, Intermountain Forest and Range Experiment Station. 